\title{
ИДЕНТИФИКАЦИЯ И КЛАССИФИКАЦИЯ РИСКОВ ГАЗОТРАНСПОРТНЫХ ПРЕДПРИЯТИЙ *
}

\author{
(c) 2018 Бабаков Александр Владимирович \\ кафедра экономики и управления предприятиями и производственными комплексами \\ Санкт-Петербургский государственный экономический университет \\ 191023, Санкт-Петербург, Садовая ул., д. 21 \\ (C) 2018 Саулин Александр Дмитриевич \\ доктор экономических наук, профессор кафедры менеджмента и инноваций \\ Санкт-Петербургский государственный экономический университет \\ 191023, Санкт-Петербург, Садовая ул., д. 21 \\ E-mail: sadeabr2013@yandex.ru
}

В статье рассматриваются специфические проблемы управления рисками предприятий газового транспорта. Решаются задачи идентификации, классификации, оценки рисков, выявления риск-факторов как причин реализации рисков. Для решения этих задач сформулированы особенности управления газотранспортными предприятиями. К ним относятся плановый и монопольный характер этих предприятий, территориальное распределение по территории России, экстремальные условия работы. На основе опроса по оценке рисков предложен подход к классификации рисков управления газотранспортными предприятиями. Для различных видов рисков приведены примеры идентификаторов рисков и риск-факторов. Отмечены отличия рисков на различных уровнях управления, в том числе между ПАО «Газпром» в целом и газотранспортным предприятием как его подсистемы. Представлена схема взаимосвязей внутренних и внешних рисков газотранспортного предприятия.

Ключевые слова: газотранспортная система, риск-менеджент, идентификация, классификация и оценка рисков, риск-факторы.

Газотранспортные предприятия в силу своих функциональных особенностей и территориальной распределенности сталкиваются с принципиально различными видами рисков отраслевого и регионального характера. Системная минимизация этих рисков - необходимое условие достижения целей газотранспортных предприятий, обеспечения надежности их функционирования и экономической эффективности. В связи с этим особую актуальность приобретает решение следующих задач:

- идентификация и классификация специфических рисков функционирования и управления газотранспортными предприятиями;

- исследование причин (риск-факторов) возникновения рисков функционирования газотранспортных предприятий;

- оценка рисков и определение методов управления ими.

Для идентификации рисков следует использовать определенное понятие риска, позволяющее уточнить суть предмета управления. На наш взгляд, наиболее приемлемым является определение, заложенное в международном стандарте ISO/IEC27005 и закрепленное национальным стандартом РФ ГОСТ Р 51897-2011/Руководство ИСО 73:2009: риск - это «Влияние неопределённости на цели... обычно выражается в виде сочетания последствий события (включая изменения в обстоятельствах) и связанной с ним возможностью возникновения». То есть под риском следует понимать сочетание последствий (потерь) и вероятности их возникновения, иначе говоря, математическое ожидание объема потерь при реализации события. При этом, как указано в этих стандартах, цели могут иметь различные аспекты (например, финансовые цели, цели охраны здоровья и безопасности, экологические цели). Применительно к конкретной организации следует распознать виды риск-факторов в различных аспектах.

Следует отметить, что в силу сравнительной новизны риск-менеджмента существует масса их классификаций - до 200 разновидностей

* ГРНТИ 068112 
в различных системах. Однако, классификация рисков должна быть конкретизирована для определенного класса системы, в связи с тем, что в каждой хозяйственной системе присутствует своя особенная структура рисков (имеются в виду различные уровни значимости). Исходя из этого, к принятым уже в литературе требованиям к системе риск-менеджмента: обеспечение приемлемого уровня рисков, контроль расходов, законность - следует добавить еще одно - управляемость. Данное требование выполняется в том случае, когда перечень идентифицируемых рисков ограничен, то есть включает в себя только те из них, которые имеют достаточно значимый уровень - по объему потерь и вероятности реализации.

Первый и самый распространенный признак классификации рисков - функциональный. В соответствии с ним выделяются финансовые, технологические, маркетинговые, социальные, организационные и другие риски.

Вторым признаком классификации рисков является место появления и распространения:

- микроуровень (уровень предприятий, потребительских хозяйств - населения);

- мезоуровень (отраслевой, региональный);

- макроуровень (уровень государства, национальной и мировой экономики).

Собственно, перечень рисков на каждом уровне выделяется также по функциональному принципу, но при этом наблюдается разная структура рисков, то есть разный состав рисков с различным уровнем значимости. Так, на макроуровне на первый план выходят политические, внешнеэкономические, социальные риски, а также риски стратегической и оборонной безопасности. На уровне производственных предприятий следует особое внимание уделять производственным, маркетинговым, инвестиционным рискам.

Третий признак классификации рисков - отраслевой. Риски отличаются в различных в отраслях народного хозяйства, в том числе в добывающей и обрабатывающей промышленности, в традиционных и инновационных секторах. Здесь также используются перечень рисков, выделенных по функциональному принципу, но в связи с использованием разных технологий, с разными масштабами производства, разными требованиями потребителей, разной стратегической значимостью для экономики страны различается не только перечень рисков и их структура по уровню значимости, но и природа риск-факторов и методов их нейтрализации. В каждом случае требуется конкретизация состава потенциальных рисков и методов работы с ними. Если рассматривать в качестве объекта управления газотранспортные предприятия, то отраслевой аспект становится важным.

Еще один признак классификации, значимый для газотранспортного предприятия - региональный, так как эти предприятия распределены на различных территориях. Здесь в качестве риск-факторов выступает разная обеспеченность ресурсами, кадрами, финансами (спросом), разная социально-экономическая политика и квалификация кадров, разные природно-географические условия.

В научных работах пока не наблюдается развернутого анализа рисков деятельности газотранспортных систем. Так, в работе [4] рассматриваются природные (климатические, географические) и техногенные риски; в диссертации Герды А.А. внимание сконцентрировано на рисках безопасности работы газотранспортных систем в связи с их аварийностью; в статье [2] рассмотрение ограничено экологическими рисками; в работе [5] риски газотранспортных систем рассматриваются в контексте модернизации газотранспортных систем (капитальный ремонт, обновление) с точки зрения ПАО «Газпром» в целом (классификация рисков соответствует позиции, отраженной на официальном сайте); наконец, в статье В.Э. Зайковского [3] дано сравнительно широкое описание рисков, но большинство из них касается ПАО «Газпром» (стратегические риски, риски отсутствия возможности продления лицензий на использование природных ресурсов и других лицензий, риски, связанные с регистрацией прав на недвижимое имущество и земельные участки) и только три риска из рассматриваемого перечня можно отнести к работе собственно газотранспортных компаний: риски, связанные с географическими и климатическими условиями, риски, связанные с эксплуатацией производственных объектов, риски, связанные с загрязнением окружающей среды.

Идентификация и классификация специфических рисков газотранспортных предприятий определяются их отраслевыми и организационно-управленческими особенностями, которые выступают как причины возникновения рисков (риск-факторов). К этим особенностям можно 
отнести следующие:

- системная цель этих предприятий транспортировка газа от входа к выходу региональной системы газоснабжения. В этой сфере отсутствует большой набор технологических переделов, характерных для сложного производства продукции (продукция уже добыта другой компанией Общества). Более того, само газотранспортное предприятие является одним из технологических переделов в вертикально интегрированном нефтегазовом комплексе (ВИНГК), то есть является локальной подсистемой этой комплекса. Это сужает набор (но не уровень) производственных рисков (важнейшая задача газотранспортной системы - сохранить, не снизить качество газа на выходе по сравнению с входом);

- цель газотранспортной системы носит не рыночный, а плановый характер (выполнение производственного плана по транспортировке газа практически в натурально-вещественной форме). Это говорит о сравнительно низком значении финансового риска от недополучения прибыли (ее снижения) и о более высоком значении производственно-эксплуатационного риска - выполнение плана в полном объеме и в срок (недовыполнение рассматривается как риск). Поскольку целевым показателем газотранспортной системы выступает не максимум результата (сбыта, прибыли, рынка потребления), а минимум затрат при заданном результате (производственном плане), то финансовые риски в этой системе должны рассматриваться именно в этом аспекте - риск превышения затрат по выполнению производственного плана, невыполнения плана по экономии затрат ресурсов и т.д.;

- спецификой газотранспортной системы является высокий уровень централизации маркетинговой функции на уровне материнской компании: максимальная централизация данной функции в области сбыта газа конечным потребителям, в меньшей степени - по материально-техническому снабжению. В этой связи можно отметить сравнительно невысокое значение стратегических сбытовых рисков для газотранспортных компаний (связанных с определением и формированием спроса, рынков потребления, планирования объемов сбыта, продвижением услуг и т.д.). Однако, сбытовые тактические риски, связанные с обеспечением качества обслуживания потребителей, закреплены за самими газотранспортными предприяти- ями, что обусловлено технологией и требованиями к качеству поставляемого товара. Сбытовые стратегические риски на газотранспортную компанию, конечно, окажут влияние, но опосредованно через финансовые риски - такие, как снижение уровня финансирования компании (инвестиции, инновации, ремонт и техническое обслуживание, оплата труда) в связи со снижением доходов ВИНГК в целом вследствие снижения спроса на газ конечных потребителей;

- с другой стороны, в рамках маркетинговой функции - в связи с целевой установкой по выполнению производственного плана, бесперебойной своевременной работе по поставкам газа - на первый план выходит необходимость сосредоточения газотранспортных компаний на рисках материально-технического обеспечения: риски своевременной поставки материально-технических ресурсов в полном объеме, обеспечения достаточного уровня их качества, правильности выбора поставщиков и видов ресурсов, определения оптимального уровня запасов. Данный риск усугубляется широкой номенклатурой требуемых материально-технических ресурсов для обслуживания, ремонта и эксплуатации - до 100 тыс. позиций;

- особенность работы газотранспортной системы - работа в экстремальных условиях с взрывоопасным предметом труда, имеющим экологическую опасность, что предъявляет повышенные требования к работе с рисками технологической и экологической безопасности;

- газотранспортные предприятия расположены по территории всей России, газотранспортная система ПАО «Газпром» является самой протяженной в мире: 179 тыс. км. Это означает еще одну особенность этих систем - большая протяженность газопроводов для поставок газа в различных географических и климатических условиях, зачастую маргинальных (водные преграды, горы, болота, леса, крупные города). В связи с этим особенностью данного объекта управления является специфическая составляющая - географические, климатические риски (в теории относятся к страновым рискам) и социально-экономические риски, связанные с неравномерностью развития различных регионов. Данные риски существенно влияют на производственные риски по эксплуатации газотранспортного оборудования, его обслуживанию, обеспечения качества работы, ремонта и риски безопасности; 
- особенность ПАО «Газпром», как крупной государственной корпорации, являющейся материнской по отношению к газотранспортным предприятиям - большая роль в государственном бюджете (особенно в экспортных доходах до $11 \%$ бюджета РФ), обеспечении народного хозяйства энергоносителями и стратегическим сырьем, повышении качества жизни населения, а также в выполнении обязательств по социальной ответственности (поддержка культуры и искусства, спорта, социально незащищенных слоев населения, экологических проектов, социального развития регионов и т.д.). В этой связи для всех ее подразделений, в том числе газотранспортных компаний, социальные риски имеют более высокое значение, чем у производственных предприятий других отраслей.

Большое влияние на состав и значимость рисков оказывает цель производственной системы. В качестве ключевого показателя работы газотранспортного предприятия выступает выполнение плана по транспортировке газа в заданных объемах сроках и качеством газа, а в качестве целевого индикатора блока управления рисками в газотранспортной системе можно выделить минимум сбоев (потерь от реализованных рисков) в поставках газа (максимальная надежность). Вследствие этого на первый план выходят технологические (производственно-эксплуатационные и ремонтные) риски, для минимизации которых требуется оптимизация работы структурных подразделений, ответственных за обоснованную оценку технического состояния, техническое обслуживание и ремонт объектов, своевременное обновление производственных мощностей с минимизацией износа оборудования, являющегося риск-фактором сбоя работы газотранспортной системы. Кроме того, исходя из отмеченных особенностей газотранспортной системы в блоке управления рисками весомую роль должны играть риски материально-технического обеспечения, риски безопасности, экологические, социальные и (в определенном аспекте) финансовые риски. Объективно, для установления приемлемой номенклатуры рисков требуется сбор статистических данных о случаях реализации риск-факторов за обозримый период с тем, чтобы оставить для постоянного мониторинга те риск-факторы, которые проявляются регулярно именно в газотранспортной системе (то есть провести отбор по объективной вероятности, хотя все равно сле- дует оставить те риск-факторы, которые при небольшом уровне статической вероятности могут привести к существенным потерям предприятия). Однако, для этого требуется значительное время, поэтому на первом этапе внедрения риск-менеджмента основой выявления необходимого перечня рисков выступает экспертная оценка.

Следует отметить, что разделение риск-факторов и конечных рисков довольно затруднительно. Различные виды рисков настолько переплетены друг с другом, что в одних случаях становятся риск-факторами, а в других - последствиями реализации риск-факторов. Так, финансовый риск может выступать как риск-фактор - при недофинансировании потребности в ремонте газопровода, и как непосредственная потеря (реализованный риск) при снижении доходов вследствие снижения объема транспорта газа в связи со снижением плана или в связи с аварией, приведшей к невыполнению плана. С другой стороны, технологический риск выступает как риск-фактор для риска невыполнения плана по транспортировке (особенно при росте уровня износа трубопровода), и как реализованный риск при аварии вследствие неправильной эксплуатации газопровода (то есть риск-фактором выступает социальный риск, связан с низким уровнем квалификации персонала) или изза природной катастрофы (климатический или географический риск-фактор).

Для выявления специфических рисков газотранспортного предприятия требуется проведение оценки рисков по степени значимости. Эта оценка была проведена на базе опроса специалистов двух предприятий (на каждом было опрошено по 200 специалистов на разных уровнях управления) из перечня рисков, сформированного предварительно экспертами. Результаты этой оценки отражены на рисунке 1 . (оценка производилась по пятибалльной шкале).

Выявленные риски с наиболее высокими оценками значимости позволили сформировать классификацию рисков газотранспортного предприятия, с которыми в первую очередь следует работать. Эти риски реализуются в соответствующих подсистемах управления производством. Газотранспортное предприятие является системой со своей ключевой целью (выполнение плана) и со своими подсистемами, для каждой из которых характерны свои особенные риски и риск-факторы: 


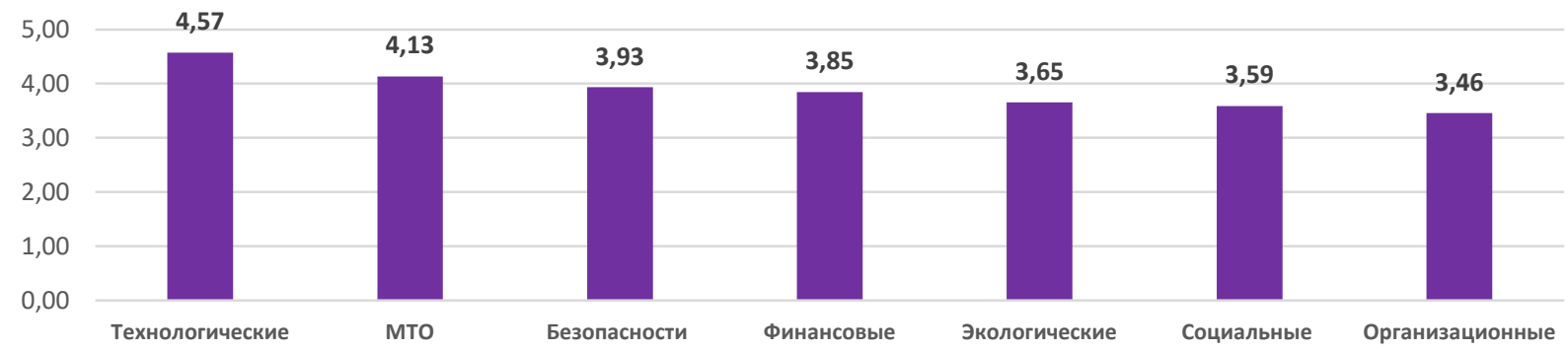

Рис.1. Оценка значимости рисков газотранспортного предприятия по пятибалльной шкале

1) технологическая подсистема эксплуатации (транспортировки газа), обслуживания и ремонта (капитального и текущего). Надежная работа технологической подсистемы во многом определяется новым строительством и модернизацией газотранспортной системы;

2) подсистема обеспечения: в первую очередь, материально-технического, энергетического, информационного, а также безопасности;

3) финансовая подсистема, основанная на финансовых целевых показателях (объемные плановые показатели и минимизация издержек) и формируемом бюджете для выполнения плана;
4) социальная подсистема, включая повышение квалификации, развитие персонала, социальное обеспечение и т.д.

5) организационная подсистема: планирование и управление, обеспечение экологической безопасности (правильно выполнение стандартизированных бизнес-процессов).

Индикаторы, риски и риск-факторы для каждой из подсистем управления газотранспортным предприятием представлены в табл. 1.

Выделенные риски, вошедшие в представленную классификацию, являются внутренними рисками. На каждый из них воздействуют определенные риск-факторы - результаты выполне-

Таблица 1. Риски различных подсистем газотранспортной системы

\begin{tabular}{|c|c|c|c|}
\hline Подсистема ГТС & Индикатор риска & Основной вид риска & $\begin{array}{c}\text { Риски, выступающие } \\
\text { причинами основного } \\
\text { вида рисков }\end{array}$ \\
\hline \multirow[t]{3}{*}{$\begin{array}{l}\text { Технологическая } \\
\text { подсистема }\end{array}$} & $\begin{array}{l}\text { Объем, сроки и качество } \\
\text { поставки }\end{array}$ & $\begin{array}{l}\text { Ключевой производ- } \\
\text { ственно-технологический }\end{array}$ & $\begin{array}{l}\text { Ремонтные, финансовые } \\
\text { социальные, безопасно- } \\
\text { сти, организационные }\end{array}$ \\
\hline & $\begin{array}{l}\text { Сроки, объемы и качество } \\
\text { работ по ТО и ремонту }\end{array}$ & $\begin{array}{l}\text { Производственно- } \\
\text { ремонтные }\end{array}$ & $\begin{array}{l}\text { Риски обеспечения, раз- } \\
\text { вития, организационные, } \\
\text { социальные, внешние } \\
\text { (финансовые) риски }\end{array}$ \\
\hline & $\begin{array}{l}\text { Сроки, объемы и качество } \\
\text { работ по новому строи- } \\
\text { тельству и капитальному } \\
\text { ремонту }\end{array}$ & Инвестиционные риски & $\begin{array}{l}\text { Финансовые, организаци- } \\
\text { онные (выбор и контроль } \\
\text { подрядчика) }\end{array}$ \\
\hline Подсистема обеспечения & $\begin{array}{l}\text { Сроки, объемы и качество } \\
\text { обеспечения }\end{array}$ & Риски МТО, безопасности & $\begin{array}{l}\text { Финансовые, организа- } \\
\text { ционно-управленческие, } \\
\text { социальные, маркетинго- } \\
\text { вые риски }\end{array}$ \\
\hline Финансовая подсистема & $\begin{array}{l}\text { Удельные издержки на } \\
\text { транспортировку }\end{array}$ & Финансовый & $\begin{array}{l}\text { Организационные (пла- } \\
\text { нирование, контроль), } \\
\text { внешние маркетинговые } \\
\text { (сбыта), экологические }\end{array}$ \\
\hline $\begin{array}{l}\text { Социальная подсистема } \\
\text { (развития) }\end{array}$ & $\begin{array}{l}\text { Квалификация и мотива- } \\
\text { ция персонала }\end{array}$ & Социальный & $\begin{array}{l}\text { Финансовые (наличие } \\
\text { средств для подготовки } \\
\text { персонала), внешние (до- } \\
\text { ступность рабочей силы } \\
\text { требуемого качества) } \\
\text { риски }\end{array}$ \\
\hline $\begin{array}{l}\text { Организационная } \\
\text { подсистема }\end{array}$ & $\begin{array}{l}\text { Качество управления } \\
\text { бизнес-процессами } \\
\text { (структура, ССП) }\end{array}$ & $\begin{array}{l}\text { Организационно-управ- } \\
\text { ленческий }\end{array}$ & $\begin{array}{l}\text { Социальные (квалифика- } \\
\text { ция управленческого пер- } \\
\text { сонала), внешние риски }\end{array}$ \\
\hline
\end{tabular}


ния конкретных бизнес-процессов. Риск-факторы, определяющие возможность выполнения ключевого показателя, требуют расшифровки. Возможный перечень таких риск-факторов для газотранспортного предприятия представлен в табл. 2.

Риск-факторы детализируются до риск-со- бытий, например, по риску отказа в капитальном ремонте (KР) оборудования:

- невыполнение со стороны подрядных организаций графиков поставки материально-технических ресурсов подрядчика на объектах КР;

- включение в акты работ, фактически не выполненных либо в завышенном объеме;

Таблица 2. Классификация внутренних рисков газотранспортной системы

\begin{tabular}{|c|c|c|}
\hline & Внутренние риски & Риск-факторы \\
\hline \multicolumn{3}{|c|}{ 1. Производственные ключевые риски } \\
\hline 1. & $\begin{array}{l}\text { Нарушение сроков } \\
\text { поставки газа }\end{array}$ & \multirow{3}{*}{$\begin{array}{l}\text { - отказ в подсистеме эксплуатации (отказы в работе производственного и } \\
\text { управленческого персонала); } \\
\text { - технологические риски подсистемы обслуживания и ремонта-отказы } \\
\text { оборудования и трубопроводов (включая аварии) из-за несвоевременного ТО } \\
\text { и ремонта; } \\
\text { - отказ из-за недостатка мощностей при реализации рисков развития; } \\
\text { - риски других подсистем, включая аварии по природным причинам }\end{array}$} \\
\hline 2. & $\begin{array}{l}\text { Нарушение объемов } \\
\text { поставки }\end{array}$ & \\
\hline 3. & $\begin{array}{l}\text { Нарушения в качестве } \\
\text { поставки }\end{array}$ & \\
\hline \multicolumn{3}{|c|}{ 2. Технологические риски обслуживания и ремонта } \\
\hline 1. & $\begin{array}{l}\text { Нарушения в сроках, } \\
\text { объемах и качестве ТО }\end{array}$ & \multirow{3}{*}{$\begin{array}{l}\text { - отказ в материально-техническом обеспечении (материалы, комплекта- } \\
\text { ция, оборудование); } \\
\text { - отказ подрядчиков (низкая квалификация, неправильный выбор, дефицит } \\
\text { финансирования); } \\
\text { - отказ из-за недостатков во внутренних бизнес-процессах, ошибок в плани- } \\
\text { ровании; } \\
\text { - отказ внутренних подразделений - низкая квалификация, дефицит персо- } \\
\text { нала }\end{array}$} \\
\hline 2. & $\begin{array}{l}\text { Нарушения в сроках, } \\
\text { объемах и качестве } \\
\text { ППР }\end{array}$ & \\
\hline 3. & $\begin{array}{l}\text { Нарушения в сроках, } \\
\text { объемах и качестве КР }\end{array}$ & \\
\hline \multicolumn{3}{|c|}{ 3. Риски обеспечения } \\
\hline 1. & $\begin{array}{l}\text { Отказ материаль- } \\
\text { но-технического обе- } \\
\text { спечения }\end{array}$ & \multirow{2}{*}{$\begin{array}{l}\text { - финансовые риски (недофинансирование потребности); } \\
\text { - отказ поставщиков - нарушения сроков, объемов и качества поставок из- } \\
\text { за низкой квалификации поставщиков (неправильный выбор); } \\
\text { - неправильный выбор ассортимента поставки; } \\
\text { - отказ из-за недостатков во внутренних бизнес-процессах, ошибок в плани- } \\
\text { ровании; } \\
\text { - отказ внутренних подразделений - низкая квалификация, дефицит персо- } \\
\text { нала }\end{array}$} \\
\hline 2. & $\begin{array}{l}\text { Отказ энергетического } \\
\text { (инфраструктурного) } \\
\text { обеспечения }\end{array}$ & \\
\hline \multicolumn{3}{|c|}{ 4. Организационные риски } \\
\hline 1. & $\begin{array}{l}\text { Отказы в принятии } \\
\text { решений (сроки и } \\
\text { ошибки) } \\
\end{array}$ & \multirow{3}{*}{$\begin{array}{l}\text { - низкая квалификация управленческого персонала; } \\
\text { - недостатки организационной структуры управления (распределение пол- } \\
\text { номочий и ответственности, дублирования функций, нарушения в документо- } \\
\text { обороте и выполнении бизнес-операций); } \\
\text { - неправильная система ключевых показателей эффективности, плановых } \\
\text { показателей, их контроля; } \\
\text { - отсутствие системы риск-менеджмента; } \\
\text { - внешние риски в стратегии управления надсистемы }\end{array}$} \\
\hline 2. & $\begin{array}{l}\text { Отказы в системе } \\
\text { планирования (сроки и } \\
\text { ошибки) } \\
\end{array}$ & \\
\hline 3. & $\begin{array}{l}\text { Отказы в организации } \\
\text { управления - срывы } \\
\text { выполнения решений и } \\
\text { планов } \\
\end{array}$ & \\
\hline \multicolumn{3}{|c|}{ 5. Риски развития } \\
\hline 1. & $\begin{array}{l}\text { Отказы из-за недостат- } \\
\text { ка производственных } \\
\text { мощностей }\end{array}$ & \multirow{2}{*}{$\begin{array}{l}\text { - срыв сроков ввода новых мощностей: отклонение графика финансирова- } \\
\text { ния, низкое качество строительных работ и/или оборудования, превышение } \\
\text { сметной стоимости проекта, низкая квалификация подрядчиков, утрата } \\
\text { основных средств в период инвестиционной фазы; } \\
\text { - неправильный выбор технологий и инноваций; } \\
\text { - неправильный выбор стратегии развития }\end{array}$} \\
\hline 2. & $\begin{array}{l}\text { Потери из-за непра- } \\
\text { вильных инноваций }\end{array}$ & \\
\hline \multicolumn{3}{|c|}{ 6. Социальные риски } \\
\hline 1 & $\begin{array}{l}\text { Отказы персонала } \\
\text { (сроки и качество вы- } \\
\text { полнение должностных } \\
\text { обязанностей) }\end{array}$ & $\begin{array}{l}\text { - неправильный отбор персонала; } \\
\text { - недостатки в системе подготовки кадров и повышения квалификации; } \\
\text { - недостатки в системе оценке результатов работы персонала; } \\
\text { - отсутствие (недостатки) системы мотивации персонала, в т.ч. из-за про- } \\
\text { блем в ССП }\end{array}$ \\
\hline
\end{tabular}


- нарушение графика производства работ подрядчиками на объектах КР;

- некачественное выполнение работ и т.д.

Помимо внутренних рисков, связанных с надежностью и эффективностью выполнения газотранспортным предприятием бизнес-процессов для достижения цели, на предприятие оказывают влияние и внешние риски, которые для него менее управляемы. Газотранспортная система является подсистемой глобальной газовой системы - ПАО «Газпром».

Риски надсистемы глобальной корпорации можно рассматривать как внешние риски первого уровня. К ним можно отнести следующие:

1) стратегические риски: риски стратегического управления (правильное определение стратегии развития), выбор и выхода на новые рынки в различных регионах, выбор направлений прокладки газопроводов, диверсификации производственной деятельности, риски реализации экологической политики;

2) маркетинговые риски: риски сбыта газа, снижения спроса на внутреннем рынке в связи с макроэкономическим ухудшением, ростом конкуренции на международном рынке, развитием производства альтернативных энергоносителей, низким качеством производства и услуг;

3) инвестиционные риски: риски реализации инвестиционных проектов в том числе нарушения графиков строительства и запуска новых проектов, превышения сметной стоимости, риски неправильного выбора технологий и новых объектов инвестирования;

4) финансовые риски: риски роста затрат на производство и транспорт газа, снижения цен на газ; неправильной финансовой политики (распределение финансовых ресурсов на основе определенных приоритетов);

5) правовые риски: риски, связанные с регистрацией прав на недвижимое имущество и земельные участки, риски отсутствия возможности продления лицензий на использование природных ресурсов и других лицензий, правовых споров с органами государственного регулирования и контрагентами.

Наконец, ПАО «Газпром» является подсистемой газовой отрасли и народнохозяйственной системы РФ, в которой генерируются внешние риски второго порядка:

1. Политические риски: международная санкционная политика, политический кризис (социальные потрясения) в странах-потребите- лях, риски изменения политики правительства, риски политических отношений с европейскими и азиатскими странами.

2. Макроэкономические риски: тарифной политики, валютные, кредитные, инфляционные риски (определяемые как государственной политикой, так и международными экономическими отношениями), политика субсидий для нетрадиционных источников энергии, риски макроэкономического положения в народном хозяйстве (стагнация, кризис, рост), снижения спроса и цен на международном рынке.

3. Правовые риски: государственного правового регулирования, связанные с изменениями правил таможенного контроля и уплаты пошлин в РФ, риски экологического контроля.

4. Страновые географические и климатические риски: условия добычи и транспортировки газа в регионах страны, природные катастрофы и аварии.

Разделение на внешние риски первого и второго порядка представляется, на первый взгляд, дублированием одних и тех же видов рисков, но с точки зрения газотранспортной подсистемы это оказывается важным, т.к. на риски первого порядка можно влиять, а риски второго порядка выступают как объективно не зависимые, их требуется прогнозировать, учитывать, оценивать, управлять ими можно на уровне народного хозяйства в целом, насколько это возможно.

Схема взаимосвязи внутренних и внешних рисков функционирования газотранспортной системы отражена на рисунке 2. Финансовые риски для газотранспортного предприятия в первую очередь формируются как внешние риски, они начинают проявляться в надсистеме и затем на самом предприятии как внутренний риск - в форме дефицита финансирования, снижения лимитов на закупки, обслуживание, ремонт и т.д. Газотранспортное предприятие генерирует финансовые риски при выполнении централизованного плана в том случае, если не выполняет план по транспортировке газа, тогда материнская компания несет потери по недополученным доходам и штрафным санкциям, что ведет к уменьшению бюджета газотранспортного предприятия.

При детализации риск-факторов по каждому событию и оценке рисков следует предусмотреть методы управления рисками, типичными из которых выступают такие направления как уклонение, принятие, снижение, перераспреде- 


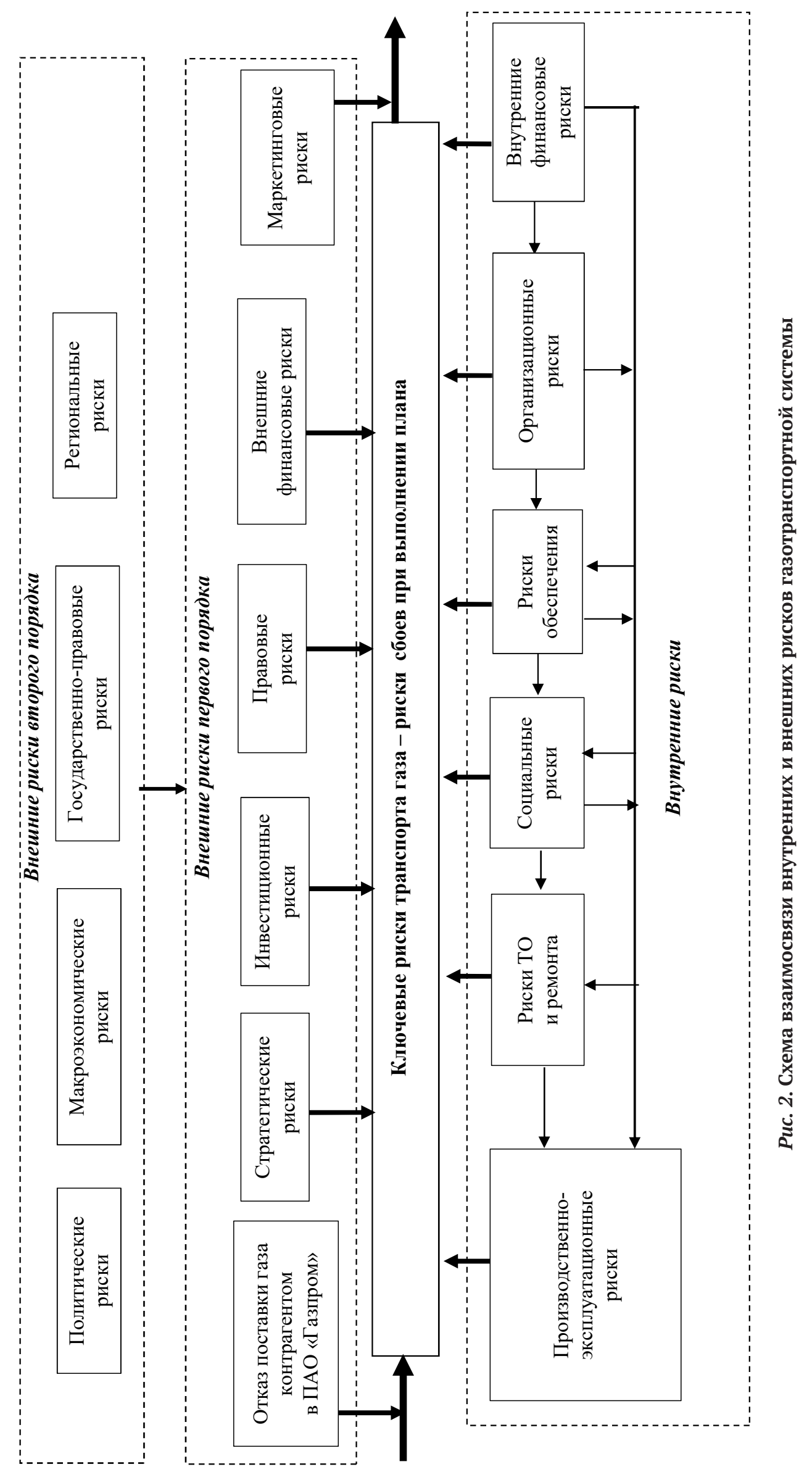


ление рисков, но это не входит в тематику данной статьи.

Из представленного анализа можно выделить следующие выводы:

1. Общая классификация рисков не может быть применена как универсальная система в различных хозяйственных системах, она должна быть детализирована и конкретизирована с учетом отраслевых и региональных особенностей предприятия и уровня управления.

2. Особенности газотранспортного предприятия, определяющего круг его рисков, заключаются в таких характеристиках как:

- целевой показатель - минимум затрат при заданном результате (план по транспортировке газа);

- плановый, а не рыночный характер производства (потребитель не конечный, а ПАО «Газпром»);

- сравнительно более высокий уровень технологических рисков производства и его обеспечения;

- существенное значение географических, климатических и социально-экономических рисков неравномерности развития регионов для территориально распределенной газотранспортной системы;

- высокая степень социальной ответственности.

3. Газотранспортное предприятие выступает в качестве подсистемы в корпорации «Газпром», поэтому стратегические и многие другие риски, присущие для ПАО «Газпром» в целом, на работу газотранспортного предприятия влияют косвенно, они являются внешними для него.

В свою очередь, отдельной задачей является выявление рисков, присущих именно для газотранспортного предприятия. Часть из них являются имманентными для него и не так значимы на уровне надсистемы. При этом количество контролируемых рисков должно быть ограничено для их управляемости.

4. На основе опроса специалистов по репрезентативной выборке из 400 человек двух газотранспортных компаний были выявлены наиболее значимые рисков: технологические риски обслуживания и ремонта; риски обеспечения ресурсами, финансовые, социальные и организационные риски.

\section{Библиографический список}

1. Герда А.А. Инновационное управление бизнес-процессами в газотранспортных предприятиях с учетом анализа техногенного и финансового рисков: Автореф...дис. ... канд. экон. наук: 08.00.05. Орел, 2007. 184 с.

2. Завгороднев А. В., Хованский А.Д., Маслова Е.В., Коняев С.В. Организация природоохранной деятельности на газотранспортных предприятиях. Учебно-методическое пособие для инженеров по охране окружающей среды / под ред. А.В. Завгороднева, А.Д. Хованского. Ставрополь: Дизайн-студия Б, 2014. 348 с.

3. Зайковский В.Э. Управление рисками газотранспортного предприятия (на примере ООО «Газпром трансгаз Томск)». // Проблемы экономики и управления нефтегазовым комплексом.- М.: ВНИИОУЭНП - 2014.№ 4.

4. Капитонова Т. А., Стручкова Г.П., Тарская Л.Е., Ефремов П.В. Анализ факторов риска трубопроводов, проложенных в условиях криолитозоны с использованием ГИС-технологий // Фундаментальные исследования, 2014. № 5-5. С. 954-958.

5. Саморукова Ю.П. Анализ рисков в условиях модернизации газотранспортного предприятия // Экономический анализ: теория и практика, 2012. № 4 (259). С. 44-52. 